\title{
Molecular profiling of a simple rat model of open tibial fractures with hematoma and periosteum disruption
}

\author{
JOSE RAFAEL VILLAFAN-BERNAL ${ }^{1-3}$, LORENZO FRANCO-DE LA TORRE $^{2,4}$, \\ ANA SOLEDAD SANDOVAL-RODRIGUEZ ${ }^{5}$, JUAN ARMENDARIZ-BORUNDA ${ }^{5}$, JUAN LUIS ALCALA-ZERMENO ${ }^{2}$, \\ JOSE ALFONSO CRUZ-RAMOS ${ }^{6}$, GABRIELA LOPEZ-ARMAS ${ }^{7}$, BLANCA ESTELA BASTIDAS-RAMIREZ ${ }^{2,8}$, \\ GRACIA VIVIANA GONZÁLEZ-ENRÍQUEZ ${ }^{9}$, EMERSON ARMANDO COLLAZO-GUZMAN ${ }^{3}$, \\ RAIGAM JAFET MARTINEZ-PORTILLA ${ }^{3}$ and SERGIO SÁNCHEZ-ENRÍQUEZ ${ }^{2}$
}

\begin{abstract}
${ }^{1}$ Young Scientist and Cathedras Department, National Council of Science and Technology (CONACYT), Mexico City 03940;
${ }^{2}$ Molecular Biology and Genomics Department, University Center for Health Sciences, University of Guadalajara, Guadalajara, Jalisco 44340; ${ }^{3}$ Surgery Department, Health Science University Center, Autonomous University of Aguascalientes, Aguascalientes, Aguascalientes 20131; ${ }^{4}$ Health Sciences Department, Los Altos University Center at Tepatitlan, University of Guadalajara, Guadalajara, Jalisco 47620; ${ }^{5}$ Institute of Molecular Biology in Medicine and Gene Therapy, University Center for Health Sciences, University of Guadalajara, Guadalajara, Jalisco 44340;

${ }^{6}$ Cancer Institute of Jalisco, Guadalajara, Jalisco 44280; ${ }^{7}$ Technical and Industrial Teaching Center (CETI) Colomos, Guadalajara, Jalisco 44638; ${ }^{8}$ Chronic and Degenerative Disease Institute; ${ }^{9}$ Methodological and Instrumental Disciplines Department, University Center for Health Sciences, University of Guadalajara, Guadalajara, Jalisco 44340, Mexico
\end{abstract}

Received January 11, 2016; Accepted July 26, 2016

DOI: 10.3892/etm.2016.3758

\begin{abstract}
Bone fractures are a worldwide public health concern. Therefore, improving understanding of the bone healing process at a molecular level, which could lead to the discovery of potential therapeutic targets, is important. In the present study, a model of open tibial fractures with hematoma disruption, periosteal rupture and internal fixation in 6-month-old male Wistar rats was established, in order to identify expression patterns of key genes and their protein products throughout the bone healing process. A tibial shaft fracture was produced using the three-point bending technique, the hematoma was drained through a 4-mm incision on the medial aspect of the tibia and the fracture stabilized by inserting a needle into the medullary canal. Radiographs confirmed that the induced fractures were diaphyseal and this model was highly reproducible (kappa inter-rater reliability, 0.82). Rats were sacrificed 5, 14, 21, 28 and 35 days post-fracture to obtain samples for histological, immunohistochemical and molecular analysis. Expression of
\end{abstract}

Correspondence to: Dr Sergio Sanchez-Enriquez, Molecular Biology and Genomics Department, University Center for Health Sciences, University of Guadalajara, Sierra Mojada 950, Guadalajara, Jalisco 44340, Mexico

E-mail: serlucis@hotmail.com

Key words: open fracture, animal model, molecular characteristics, gene expression, bone proteins, osteoporosis, bone, osteocalcin, bone morphogenetic proteins interleukin-1 $\beta$ (Il-1 $\beta)$, transforming growth factor- $\beta 2$ (Tgf- $\beta 2)$, bone morphogenetic protein-6 (Bmp-6), bone morphogenetic protein-7 (Bmp-7) and bone $\gamma$-carboxyglutamic acid-containing protein (Bglap) genes was determined by reverse transcription quantitative polymerase chain reaction and protein expression was evaluated by immunohistochemistry, while histological examination allowed characterization of the bone repair process. Il- $1 \beta$ showed a biphasic expression, peaking 5 and 28 days post-fracture. Expression of $T g f-\beta 2, B m p-6$ and Bmp-7 was restricted to the period 21 days post-fracture. Bglap expression increased gradually, peaking 21 days post-fracture, although it was expressed in all evaluated stages. Protein expression corresponded with the increased expression of their corresponding genes. In conclusion, a clear and well-defined expression pattern of the evaluated genes and proteins was observed, where their maximal expression correlated with their known participation in each stage of the bone healing process.

\section{Introduction}

Bone fractures have become a worldwide public health concern due to their increasing incidence, the cost of treatment and resulting absenteeism in the workplace (1-3). Experimental models have been used in previous studies to test novel therapies for the facilitation and acceleration of fracture healing (4-10); however, these are not representative of all clinical situations, such as when a hematoma is drained and/or the periosteum is disrupted. Hematoma and periosteum disruption are common clinical scenarios in tibial open fractures in humans $(11,12)$ and increase the risk of delayed union, late union and non-union $(13,14)$. Therefore, it is important to have experi- 
mental models that reflect these situations in order to study the gene and protein expression patterns specific to these scenarios.

Fracture hematomas are a source of growth factors and cytokines, such as platelet-derived growth factor (PDGF), vascular endothelial growth factor (VEGF), transforming growth factor- $\beta 2$ (TGF- $\beta 2$ ) and interleukin-1b (IL-1 $\beta$ ) (15-17). These growth factors promote fracture healing and induce the expression of a number of molecules important for bone repair, such as osteocalcin and bone morphogenetic proteins (Bmps) (15-17). During fracture healing, periosteal cells serve a primary role in cartilage and bone formation within the callus (18). The periosteum is a complex structure that is a repository for pluripotent stem cells and molecular factors that modulate cell behavior (18).

Instruments that have been designed to reproduce long bone fractures in small species, such as rats and mice, are composed of at least four parts: i) A frame, ii) an animal support system, iii) a guillotine ramming system and iv) a steel weight, similar to the one first described by Bonnarens and Einhorn (4), which has been reproduced and modified by other research groups (4-10). Manufacturing these devices is an expensive and time-consuming process (4-10). In addition, devices used for the internal fixation of long bone diaphyseal fractures in rats and mice typically have a very small diameter $(<1 \mathrm{~mm})$ and are difficult to obtain in the majority of countries (4-10). In the present study, a rat model of open tibial fractures with hematoma disruption, periosteal rupture and a versatile intramedullary fixation system was established in order to determine gene and protein expression throughout the bone healing process.

\section{Materials and methods}

Experimental animals. Forty 6-month-old male Wistar rats weighing $350 \pm 20 \mathrm{~g}$ were obtained from the University Center for Health Sciences Animal Research Facility (University of Guadalajara, Guadalajara, Mexico). All animals were housed in a standard laboratory animal environment under a 12:12-h light cycle in a controlled environment with a temperature of $23 \pm 2^{\circ} \mathrm{C}$ and humidity of $50 \pm 10 \%$. The rats had ad libitum access to food and water.

All procedures were approved by the local Committee of Ethics and Biosecurity at University Center for Health Sciences (Guadalajara, Mexico) and performed in accordance with animal protection protocols in Mexico (NOM-062-ZOO-1999).

Fracture production and stabilization. A tibial fracture model was designed to simulate open fractures treated with open reduction and internal fixation. Rats were anesthetized using Zoletil $^{\circledR}$ (Virbac, Guadalajara, Mexico; $5 \mathrm{mg} / \mathrm{kg}$ ) and surgically prepared prior to fracture and analgesia was continued for $72 \mathrm{~h}$ post-surgery. Intramuscular cephalothin $(40 \mathrm{mg} / \mathrm{kg})$ was administered $30 \mathrm{~min}$ prior to surgery and $24 \mathrm{~h}$ following surgery.

The right tibia of the rats was fractured by one of two researchers using a manual three-point bending technique (Fig. 1A). In addition, the right fibula was fractured. The rats were then placed in five groups (each $n=6$ ) for sacrifice at five different time points. Following fracture, a 4-mm incision was made over the medial side of the tibia, the hematoma was drained and the periosteum was opened (Fig. 1B). The fracture was stabilized using a hypodermic $22 \mathrm{G}(0.7 \times 38 \mathrm{~mm})$ or $20 \mathrm{G}(0.9 \times 38 \mathrm{~mm})$ needle that served as an intramedullary rod (Fig. 1C-F). For internal fixation a guide needle was introduced in a retrograde fashion from site of fracture towards the tibial tuberosity, then a fixation needle was passed in an anterograde fashion through the medullary canal from the tibial tuberosity towards the fracture site in order to stabilize the bone fragments. The base of the needle was cut and the incisions were closed using nylon 3-0 sutures. The length of time from fracture to skin closing was recorded.

To verify correct needle positioning, an X-ray was performed in $50 \%$ of the test subjects that were chosen at random. Radiographs showed that the majority of the induced fractures were diaphyseal with short oblique or transverse lines, regardless of which investigator performed the fracture or the force applied (Fig. 1F). There were two cases of complex fracture. The reproducibility of the fracture technique was evaluated using the inter-rater reliability Cohen Kappa statistic (19). Before the present study, different surgical approaches were used until reproducible hematoma and periosteal disruption were achieved, and to find the best fixation material.

Rats in the five groups were sacrificed using an intraperitoneal injection of $\geq 200 \mathrm{mg} / \mathrm{kg}$ sodium pentobarbital (Pisabental ${ }^{\circledR}$; Pisa Laboratories, Tlajomulco de Zuniga, Mexico) at 5, 14, 21, 28 and 35 days post-fracture, respectively, in order to harvest tissue for histology, immunohistochemistry and molecular analysis.

Histological analysis. Immediately following sacrifice the fractured tibia were harvested and fixed in $4 \%$ paraformaldehyde in phosphate-buffered saline at $4^{\circ} \mathrm{C}$ for 3 days. Specimens were then completely decalcified using Immunocal Decalcifier (StatLab, McKinney, TX, USA), embedded in paraffin and cut into $7-\mu \mathrm{m}$ sections. Sections were stained with hematoxylin and eosin for conventional histology. Sections were examined for evidence for bone healing using light microscopy at x10, x40 and x100 magnification and representative images captured.

Immunohistochemical analysis. Immunohistochemical analysis was performed on tissue from the fracture site at the time of maximum expression of the respective genes. The sections described above were dewaxed and heat-mediated antigen retrieval was performed using the pressure cooker method with citrate buffer at pH 6.0 for $25 \mathrm{~min}$. Tissues were washed in $0.1 \mathrm{M}$ phosphate-buffered saline (PBS) three times for 5 min each time. After this, slides were placed in PolyDetector AP Blocker (cat. no. BSB 0055; Bio-SB, Inc., Santa Barbara, CA, USA) for $5 \mathrm{~min}$ and washed in 0.1 M PBS buffer three times for 5 min each time. Following this, immunohistochemical staining was carried out using antibodies obtained from Abcam (Cambridge, MA, USA). The tissues were incubated with the primary antibodies overnight al $4^{\circ} \mathrm{C}$ : Anti-Bmp-7 (cat. no. ab15640; 1:50 dilution), anti-Bmp-6 (cat. no. ab56023; 1:50 dilution), anti-Tgf- $\beta 2$ (cat. no. ab53778; 1:50 dilution), anti-Il-1 $\beta$ (cat. no. ab9722; 1:50 dilution) and anti-osteocalcin (cat. no. ab13420; 1:50 dilution). Subsequently, tissues were washed in $0.1 \mathrm{M}$ PBS buffer three times for $5 \mathrm{~min}$ each time. Immunohistochemical staining was continued using a Dako LSAB System-HRP system (K0675; Agilent Technologies, USA); the biotinylated secondary antibody and streptavidin-conjugated horseradish peroxidase were used according to the manufacturer's protocol. Immunodetection was performed using diaminobenzidine tetrahydrochloride (DAB; Sigma-Aldrich; Merck Millipore, Darmstadt, Germany). Slides were counterstained with hematoxylin for 2 min (cat. 

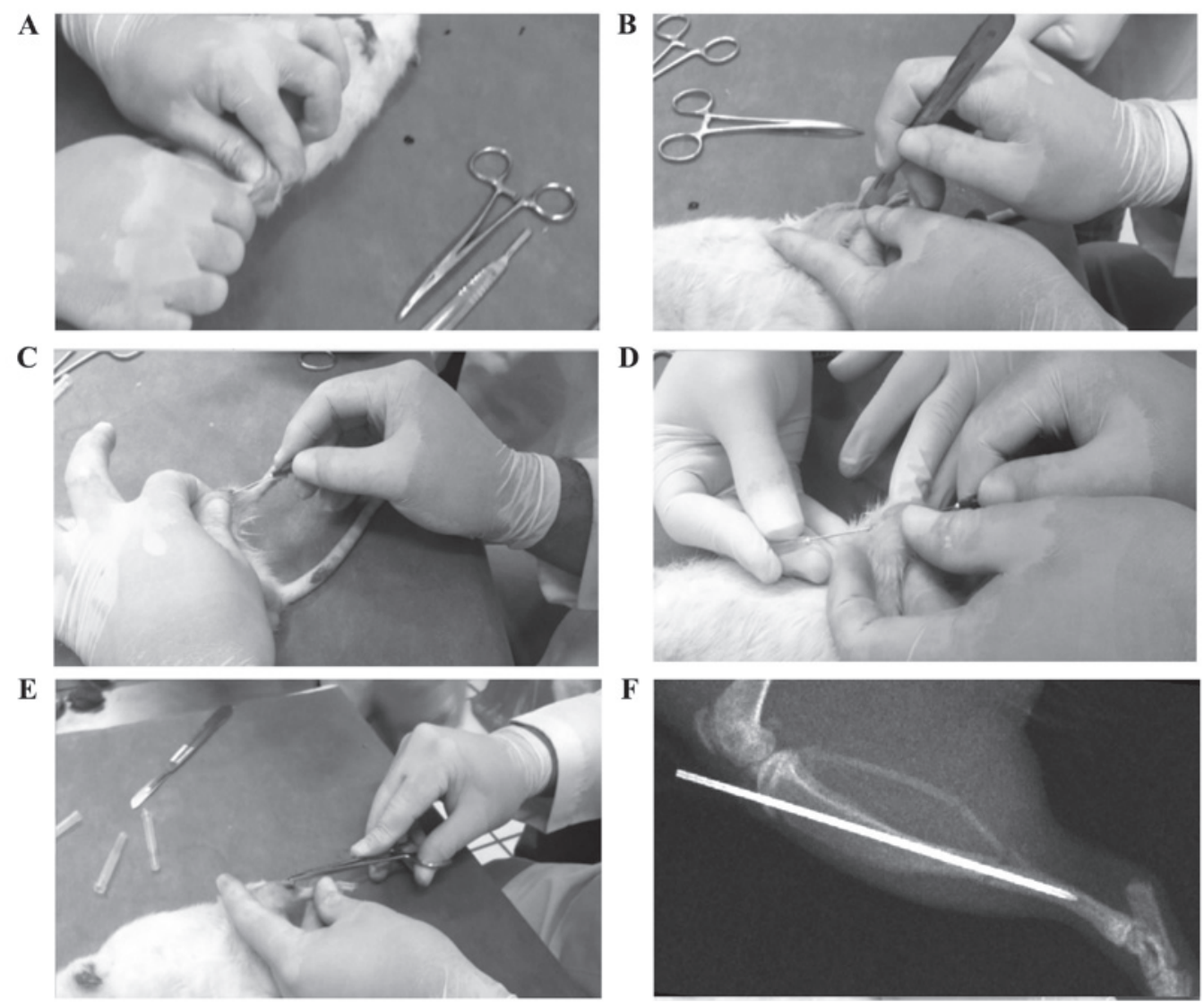

Figure 1. Tibial fracture production method. (A) Manual three-point bending fracture technique. (B) An incision (4 mm) and dissection of fracture site was performed, followed by (C) introduction of a hypodermic needle from the fracture site toward the tibial tuberosity and (D) a fixation needle from the tibial tuberosity toward the fracture site to stabilize bone fragments. (E) Wound closure following surgery. (F) Example radiograph demonstrating the fracture line following insertion of the needle.

no. BSB 0024; Bio-SB, Inc.) and mounted with Entellan ${ }^{\circledR}$ (cat. no. 107960; Merck-Millipore). Antibodies Bmp-6, Bmp-7, Tgf- $\beta 2$, Il-1 $\beta$, and Bglap (osteocalcin) were chosen because of their distinctive expression profiles in different stages of bone healing (inflammation, cartilage formation, cartilage resorption, primary bone formation, bone resorption and secondary bone formation) (20). Tissues were visualized by light microscopy using an optical microscope with 40X objective (Motic BA210; Carlsbad, CA, USA).

Molecular analysis. Gene expression of Bmp-6, Bmp-7, Tgf- $\beta 2$, $I l-1 \beta$, and Bglap was determined using reverse transcription-quantitative polymerase chain reaction (RT-qPCR). Total RNA was extracted using TRIzol reagent with the PureLink Micro-to-Midi Total RNA Purification System (Invitrogen; Thermo Fisher Scientific, Inc., Waltham, MA, USA). Extracted RNA was quantified using spectrophotometry (NanoDrop 2000C; Thermo Scientific, Inc.). RT-qPCR was performed in two phases: Complementary DNA (cDNA) synthesis and mRNA expression measurements. Firstly, cDNA synthesis for each gene was carried out using a High Capacity cDNA Reverse Transcription kit (cat. no. 4368814; Thermo Scientific, Inc.). The final reaction contained $2 \mu \mathrm{g}$ total RNA, $240 \mathrm{ng}$ random primers, 2 units RNase inhibitor, $10 \mathrm{mM}$ DTT, $0.5 \mathrm{mM}$ dNTPs and 200 units reverse transcriptase. The following conditions were used: $65^{\circ} \mathrm{C}$ for $5 \mathrm{~min}, 4^{\circ} \mathrm{C}$ for $5 \mathrm{~min}, 25^{\circ} \mathrm{C}$ for $10 \mathrm{~min}, 37^{\circ} \mathrm{C}$ for $50 \mathrm{~min}, 70^{\circ} \mathrm{C}$ for $15 \mathrm{~min}$ and $4^{\circ} \mathrm{C}$ for $5 \mathrm{~min}$.
Secondly, mRNA expression measurements was performed by qPCR using a Rotor Gene 3000 Thermocycler (Corbett Research; Qiagen GmbH, Hilden, Germany) under the following conditions: 1 cycle at $50^{\circ} \mathrm{C}$ for $2 \mathrm{~min}$; 1 cycle at $94^{\circ} \mathrm{C}$ for $5 \mathrm{~min} ; 45$ cycles at $94^{\circ} \mathrm{C}$ for $30 \mathrm{sec}$; and 45 cycles at $60^{\circ} \mathrm{C}$ for $40 \mathrm{sec}$. For the reaction, $2 \mu \mathrm{g}$ cDNA ( $9 \mu \mathrm{l}$ final volume) was used with $10 \mu \mathrm{l}$ TaqMan ${ }^{\circledR}$ Universal Master Mix II (cat. no. 4440049; Applied Biosystems; Thermo Fisher Scientific, Inc.) and $1 \mu \mathrm{l}$ TaqMan probe and primer sets (TaqMan ${ }^{\circledR}$ Gene Expression Assay; Applied Biosystems) for $I l-1 \beta$ (cat. no. Rn00676330_m1), Tgf- $\beta 2$ (cat. no. Rn00579674_m1), Вmp-6 (cat. no. Rn00432095_m1), Bmp-7 (cat. no. Rn01528889_m1), Bglap (cat. no. Rn00566386_g1) and Gapdh (RHK-1; Real Time Primers LLC, Elkins Park, PA, USA). The TaqMan probe and primer set used is a fluorophore-based detection system containing FAM-MGB dye and quencher, allowing quantitative measurements of the accumulated product during the exponential stages of PCR. Finally, levels of gene expression were calculated using the $2^{-\Delta \Delta C q}$ method described by Livak and Schmittgen (21).

Statistical analysis. Descriptive and inferential statistical analysis was performed using SPSS version 17.0 (SPSS, Inc., Chicago, IL, USA). One-way analysis of variance was used to compare means between groups. To identify the reproducibility of the fracture model between operators the Kappa Cohen coefficient was used. Chi-squared test was used to compare qualitative variables. $\mathrm{P}<0.05$ was considered to indicate a statistically significant result. 

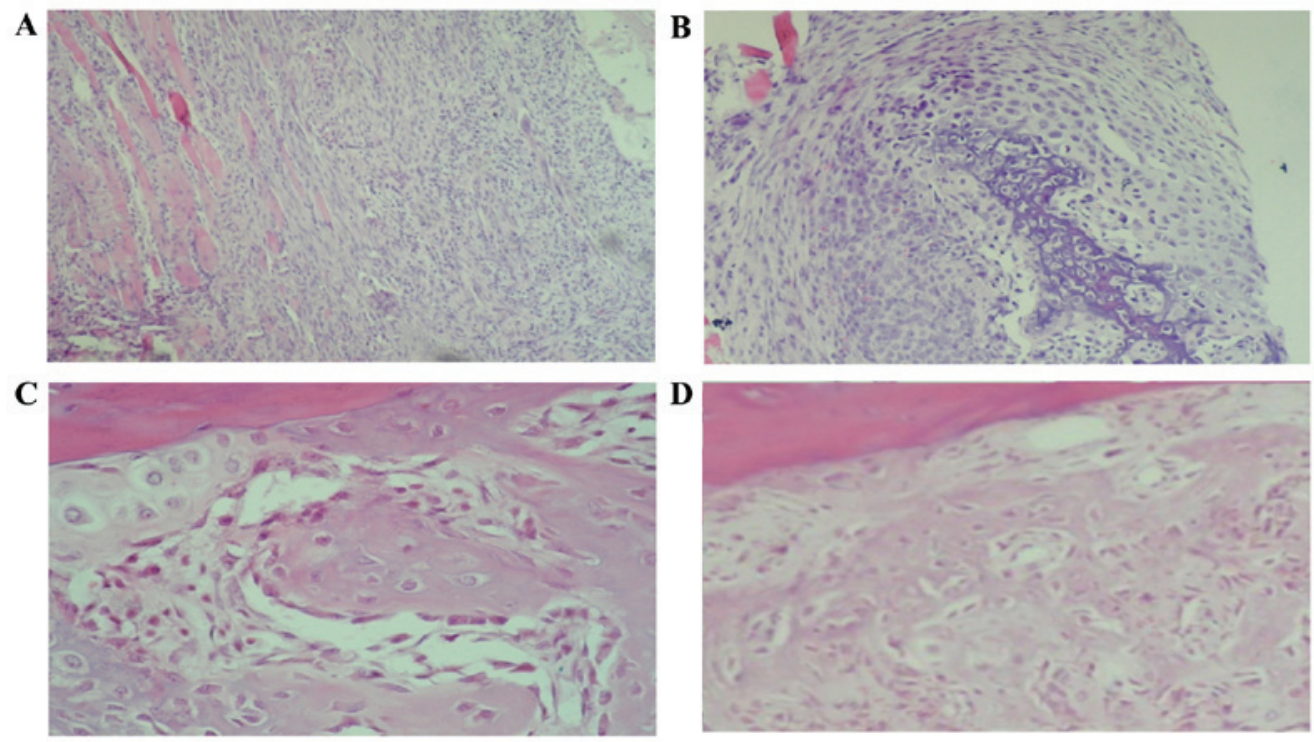

$\mathbf{E}$
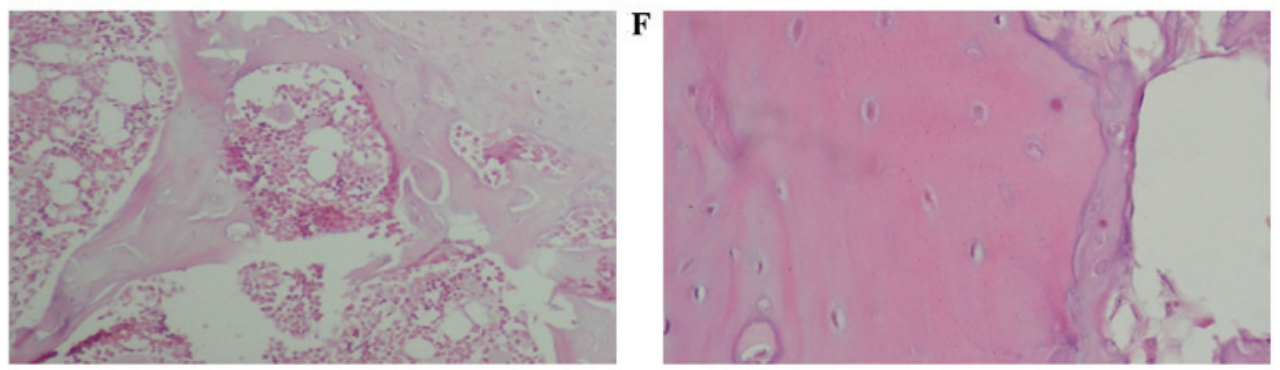

Figure 2. Histological evaluation of bone healing at 5, 14,21, 28 and 35 days post-fracture. Sections of tissue from the fracture site were stained with hematoxylin \& eosin. (A and B) show abundant inflammatory infiltrate 5 days post-fracture (magnification, $x 10)$. (C) Abundant cartilage formation and primary bone formation were observed 14 days post-fracture (x40 magnification). (D) Primary bone formation 21 days post-fracture (x10 magnification). (E) Trabecular zone at fracture site 28 days post-fracture, in which secondary bone is observed (x10 magnification). (F) Zone of cortical bone at fracture site 35 days post-fracture, displaying typical histological characteristics of a normal non-fractured bone (x40 magnification).

\section{Results}

Evaluation of fracture production method. The mean elapsed time from tibial fracture to closure of the incision was $3.8 \pm 0.44 \mathrm{~min}$ and was equivalent in all groups $(\mathrm{P}=0.711)$. The Cohen Kappa inter-rater coefficient for the type of fracture produced by the two researchers was 0.82 , indicating high reproducibility. All fractures (performed as shown in Fig. 1-E) exhibited minimal displacement of the bone ends $(<0.5 \mathrm{~mm})$, as determined by random radiographic examination (Fig. 1F), and no surgical complications (infection, surgical wound dehiscence or fracture rotation-separation) were identified.

Histological analysis of fracture healing. On day 5 post-fracture, inflammation was predominant (Fig. 2A and B), while 14 days following fracture there were numerous zones of cartilage and primary bone formation (Fig. 2C). On day 21 post-fracture, the formation of a large amount of primary bone was observed (Fig. 2D). On day 28 post-fracture, a histological pattern compatible with primary bone resorption and secondary bone formation was identified, while 35 days following fracture a completely calcified bone and histologically normal bone area was observed (Fig. 2E and F).

Gene expression patterns during fracture healing. Gapdh gene was used as a control for gene expression (Fig. 3A).
Molecular analysis revealed a biphasic peak of $\mathrm{Il}-1 \beta$ expression in the fractured tibia, the first on day 5 and the second on day 28 following fracture (Fig. 3B). During the first peak, $I l-1 \beta$ expression increased 36 -fold by day 5 post-fracture and then decreased until day 21 (Fig. 3B). The second peak was a 37-fold increase (from basal levels) on day 28 (Fig. 3B). Tgf- $\beta 2$ was expressed from day 5 to day 21 when it reached its highest levels equivalent to 8 times its basal level, prior to dropping on days 28 and 35 to reach basal levels (Fig. 3B). Bglap expression increased from day 5 until day 28 as follows: A 2-fold increase on day 5, a 32-fold increase on day 14 and a 51-fold increase on day 21 when it reached its peak expression level (Fig. 3B). On day 28, the relative expression level of Bglap dropped to 3.5-fold and normalized at day 35 (Fig. 3B). Bmp-6 was consistently expressed throughout the fracture healing processes, whereas Bmp-7 expression increased 14-fold 14 days post-fracture, reaching a peak of 26 times its basal level on day 21 (Fig. 3C).

Protein expression patterns during fracture healing. Expression of the protein products of $I l-1 \beta, T g f-\beta 2, B m p-6$, Bmp-7 and Bglap was confirmed by immunohistochemistry. Immunohistochemical analysis was performed on tissue from the fracture site at the time of maximum expression of their respective genes. At this time all of the studied proteins were found to be markedly expressed (Fig. 4). 
A

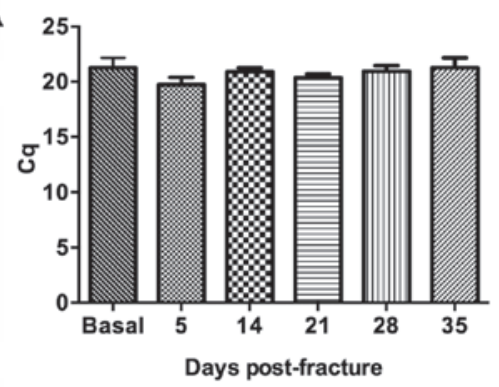

B

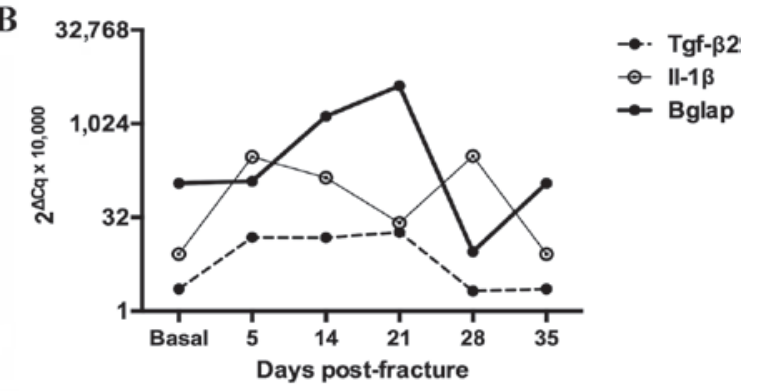

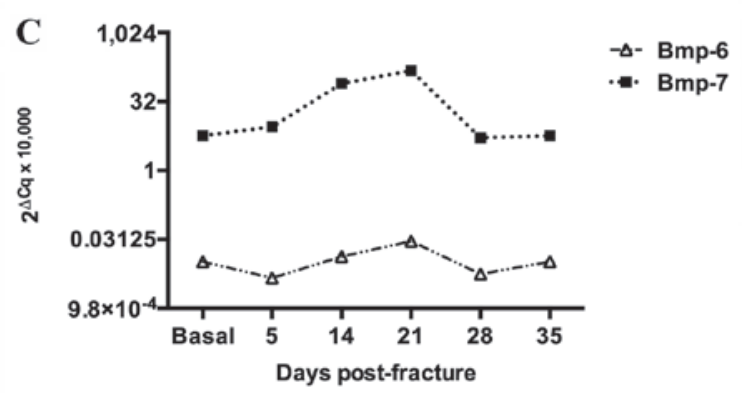

Figure 3. Molecular profiling of $I l-1 \beta$, Tgf- $\beta 2$, Bglap, Bmp-7 and Bmp- 6 gene expression during the bone healing process. Messenger RNA levels of the studied genes were analyzed by reverse transcription-quantitative polymerase chain reaction. (A) Expression of the control, Gadph, showing stable expression levels. (B) Expression levels of $I l-1 \beta, T g f-\beta 2$ and Bglap. (C) Expression levels of Bmp-6 and Bmp-7. Tgf- $\beta 2$, transforming growth factor $\beta 2$; IL-1 $\beta$, interleukin-1 $\beta$; Bglap, bone $\gamma$-carboxyglutamic acid-containing protein; Bmp-6, bone morphogenetic protein-6; Bmp-7, bone morphogenetic protein-7.
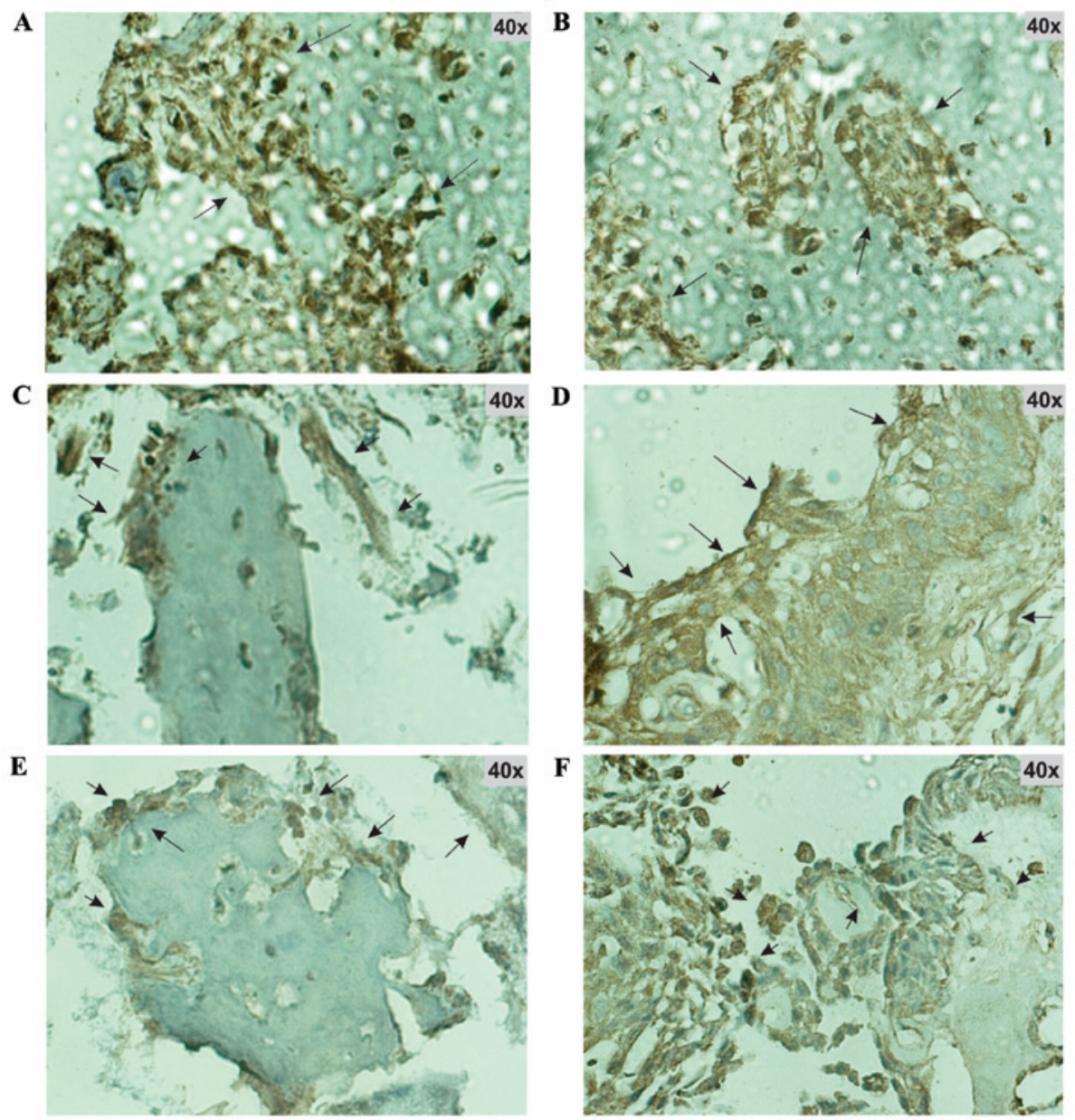

Figure 4. Protein expression of Il-1 $\beta$, Tgf- $\beta 2$, Bglap, Bmp-7 and Bmp-6 at the time of maximum expression of their respective genes. Immunohistochemistry was used to determine levels of functional protein of the studied genes. (A) and (B) Il-1 $\beta 5$ days post-fracture. (C) Tgf- $\beta 25$ days post-fracture. (D) Bglap 21 days post-fracture. (E) Bmp-6 21 days post-fracture. (F) Bmp-7 21 days post-fracture. Tgf- $\beta 2$, transforming growth factor $\beta 2$; IL-1 $\beta$, interleukin-1 $\beta$; Bglap, bone $\gamma$-carboxyglutamic acid-containing protein; Bmp-6, bone morphogenetic protein-6; Bmp-7, bone morphogenetic protein-7. Arrows and brown color indicate sites of protein expression. 


\section{Discussion}

The present study introduces a simple and highly reproducible fracture model, which can be used for future research on therapies aimed at improving the bone healing process. This method will be more accessible for developing countries, because the fracture is manually produced and the hypodermic needle (0.7-0.9 $\mathrm{mm}$ diameter) required for internal fixation of the fracture is readily available. By contrast, other experimental models of long bone fracture in small species require materials that are difficult to obtain and/or specialized equipment for fracture reproduction and stabilization. For example, the apparatus used by Bonnarens and Einhorn (4) to fracture rat femurs was made of four parts and was followed by the use of $0.45 \mathrm{~mm}$ Steinmann pins to stabilize these fractures. Hiltunen et al (5) modified this apparatus to achieve a reproducible tibia fracture in mice and used $0.2 \mathrm{~mm}$ stainless steel rods to stabilize these fractures (5). Kon et al (6) used the fracture technique of Bonnarens and Einhorn (4) and 23-25 G spinal needles as internal fixators, whereas Nakajima et al (7) used a modified version of the fracture technique used by Bonnarens and Einhorn (4) and $1.1 \mathrm{~mm}$ Kirschner wires as internal tutors to stabilize fractures. Techniques used by a number of other studies, to reproduce and stabilize diaphyseal fractures of mouse and rat tibias, are modifications of the previously described models (8-10).

The fracture model used in the current study reproduces two scenarios frequently encountered in human open tibial fractures, namely, hematoma rupture and periosteal disruption. These situations increase the risk of delayed consolidation and non-union, due to their importance in the bone healing process, particularly the loss of growth factors that occurs if the hematoma is disrupted (13-18). The reproduction of these conditions is one of the benefits that the model used in the present study offers. The characterization of the expression profiles of gene and proteins throughout the bone healing process in the current study is important since it more accurately reflects what occurs in human open tibial fractures.

A clear expression pattern for each studied gene and its respective protein was noted at every stage of bone healing process. In agreement with previous findings $(20,22)$, when inflammatory cells predominated (day 5 post-fracture), gene and protein expression of $I l-1 \beta$ increased. This cytokine is highly expressed during the early stages of bone healing, where it induces osteoblast proliferation and a slight acceleration in endochondral ossification, which facilitates bone formation $(20,22)$. Expression of $I l-1 \beta$ gene and protein was also markedly increased 28 days following fracture, when bone remodeling and secondary bone formation were observed via histological analysis. During this phase, Il-1 $\beta$ contributes to bone remodeling and mineralization $(6,20)$.

$T g f-\beta 2$ expression between days 5 and 21 reflects its role in cartilage formation, the periosteal response and endochondral ossification, as described in previous reports $(6,20)$. In addition, Tgf- $\beta 2$ induces chondrocyte proliferation in the early stages of bone healing $(20,23)$.

Bmps are essential to bone biology and fracture healing, due to their role in inflammatory response modulation, cartilage formation, the periosteal response, cartilage resorption and primary bone formation (20). The constitutive expression of $B m p-6$ throughout the fracture healing processes in the current study has been previously reported (8). Bmp-7 participates in osteoclast recruitment and cartilage resorption (20). Bmp-7 was identified to be strongly expressed from day 14 to 21 post-fracture, reaching its peak level on day 21 , when cartilage resorption and primary bone formation are highly active $(8,20)$.

Bglap is expressed abundantly in the bone, particularly during the mineralization stage of osteogenesis $(20,24,25)$. In the present study, Bglap in the majority of the cases, had the highest expression levels of all the studied genes, basally and in every time point measured of the bone healing process. The protein product of Bglap, osteocalcin, is the most abundant non-collagenous protein in the bone $(24,25)$. Osteocalcin has a high affinity for calcium and hydroxyapatite, and serves as a chemoattractant and activator for cells with bone resorption properties $(24,25)$. These functions make osteocalcin essential for bone health, bone remodeling and bone healing.

In conclusion, in the present study a simple rat model of tibial open fractures with hematoma and periosteal disruption was established, which produced clear and well-defined expression patterns for $I l-1 \beta, T g f-\beta 2, B m p-6, B m p-7$ and Bglap and their protein products throughout the bone healing process. This model will stimulate further research in the area of bone healing, particularly in the testing of therapeutic interventions aimed at enhancing the bone-formation process.

\section{References}

1. Brooks PM: The burden of musculoskeletal disease-a global perspective. Clin Rheumatol 25: 778-781, 2006.

2. Johnell $\mathrm{O}$ and Kanis JA: An estimate of the worldwide prevalence and disability associated with osteoporotic fractures. Osteoporos Int 17: 1726-1733, 2006.

3. Riera-Espinoza G: Epidemiology of osteoporosis in Latin America 2008. Salud Publica Mex 51 (Suppl 1): S52-S55, 2009.

4. Bonnarens F and Einhorn TA: Production of a standard closed fracture in laboratory animal bone. J Orthop Res 2: 97-101, 1984.

5. Hiltunen A, Vuorio E and Aro HT: A standardized experimental fracture in the mouse tibia. J Orthop Res 11: 305-312, 1993.

6. Kon T, Cho TJ, Aizawa T, Yamazaki M, Nooh N, Graves D, Gerstenfeld LC and Einhorn TA: Expression of osteoprotegerin, receptor activator of NF-kappaB ligand (osteoprotegerin ligand) and related proinflammatory cytokines during fracture healing. J Bone Miner Res 16: 1004-1014, 2001.

7. Nakajima F, Ogasawara A, Goto K, Moriya H, Ninomiya Y, Einhorn TA and Yamazaki M: Spatial and temporal gene expression in chondrogenesis during fracture healing and the effects of basic fibroblast growth factor. J Orthop Res 19: 935-944, 2001.

8. Cho TJ, Gerstenfeld LC and Einhorn TA: Differential temporal expression of members of the transforming growth factor beta superfamily during murine fracture healing. J Bone Miner Res 17: 513-520, 2002

9. Thompson Z, Miclau T, Hu D and Helms JA: A model for intramembranous ossification during fracture healing. J Orthop Res 20: 1091-1098, 2002.

10. Wildemann B, Schmidmaier G, Brenner N, Hüning M, Stange R, Haas NP and Raschke M: Quantification, localization, and expression of IGF-I and TGF-betal during growth factor-stimulated fracture healing. Calcif Tissue Int 74: 388-397, 2004.

11. Court-Brown CM, Rimmer S, Prakash U and McQueen MM: The epidemiology of open long bone fractures. Injury 29: 529-534, 1998.

12. Court-Brown CM and McBirnie J: The epidemiology of tibial fractures. J Bone Joint Surg Br 77: 417-421, 1995.

13. Papakostidis C, Kanakaris NK, Pretel J, Faour O, Morell DJ and Giannoudis PV: Prevalence of complications of open tibial shaft fractures stratified as per the Gustilo-Anderson classification. Injury 42: 1408-1415, 2011. 
14. Gaebler C, Berger U, Schandelmaier P, Greitbauer M, Schauwecker HH, Applegate B, Zych G and Vécsei V: Rates and odds ratios for complications in closed and open tibial fractures treated with unreamed, small diameter tibial nails: A multicenter analysis of 467 cases. J Orthop Trauma 15: 415-423, 2001.

15. Kolar P, Schmidt-Bleek K, Schell H, Gaber T, Toben D, Schmidmaier G, Perka C, Buttgereit F and Duda GN: The early fracture hematoma and its potential role in fracture healing. Tissue Eng Part B Rev 16: 427-434, 2010.

16. Marsell R and Einhorn TA: The role of endogenous bone morphogenetic proteins in normal skeletal repair. Injury 40 (Suppl 3): S4-S7, 2009.

17. Grundnes $\mathrm{O}$ and Reikerås $\mathrm{O}$ : The importance of the hematoma for fracture healing in rats. Acta Orthop Scand 64: 340-342, 1993.

18. Colnot C, Zhang X and Knothe Tate ML: Current insights on the regenerative potential of the periosteum: Molecular, cellular, and endogenous engineering approaches. J Orthop Res 30: $1869-1878,2012$

19. Landis JR and Koch GG: The measurement of observer agreement for categorical data. Biometrics 33: 159-174, 1977.
20. Ai-Aql ZS, Alagl AS, Graves DT, Gerstenfeld LC and Einhorn TA: Molecular mechanisms controlling bone formation during fracture healing and distraction osteogenesis. J Dent Res 87: 107-118, 2008.

21. Livak KJ and Schmittgen TD: Analysis of relative gene expression data using real time quantitative PCR and the 2-(Delta Delta C(T)) method. Methods 25: 402-408, 2001.

22. Lange J, Sapozhnikova A, Lu C, Hu D, Li X, Miclau T III and Marcucio RS: Action of IL-1beta during fracture healing. J Orthop Res 28: 778-784, 2010.

23. Wildemann B, Schmidmaier G, Ordel S, Stange R, Haas NP and Raschke M: Cell proliferation and differentiation during fracture healing are influenced by locally applied IGF-I and TGF-beta1: Comparison of two proliferation markers, PCNA and BrdU. J Biomed Mater Res B Appl Biomater 65: 150-156, 2003.

24. Hauschka PV, Lian JB, Cole DE and Gundberg CM: Osteocalcin and matrix Gla protein: Vitamin K-dependent proteins in bone. Physiol Rev 69: 990-1047, 1989.

25. Villafán-Bernal JR, Sánchez-Enríquez S and Muñoz-Valle JF: Molecular modulation of osteocalcin and its relevance in diabetes (Review). Int J Mol Med 28: 283-293, 2011. 